\title{
An assessment of sexual and gender based violence in Wajir district, North Eastern Kenya
}

Gladys K. Mwangi

Jaldesa Guyo

Follow this and additional works at: https://knowledgecommons.popcouncil.org/departments_sbsr-rh

Part of the Demography, Population, and Ecology Commons, Domestic and Intimate Partner Violence Commons, Family, Life Course, and Society Commons, Gender and Sexuality Commons, International Public Health Commons, Medicine and Health Commons, and the Women's Health Commons How does access to this work benefit you? Let us know!

\section{Recommended Citation}

Mwangi, Gladys K. and Jaldesa Guyo. 2009. "An assessment of sexual and gender based violence in Wajir district, North Eastern Kenya." Nairobi: Population Council. 
An Assessment of Sexual and Gender Based Violence in Wajir District, North Eastern Kenya

Population Council 


\section{An Assessment of Sexual and Gender Based Violence in Wajir district, North Eastern Kenya}

Reproductive Health Programme, Population Council

Gladys K. Mwangi

Guyo W. Jaldesa

January 2009 


\section{ACKNOWLEDGEMENTS}

The authors would like to acknowledge several individuals for their important role in the study. Sincere thanks go to Ms. Janet Munyasya in the Population Council's Nairobi office, who provided valuable administrative support during the study and was responsible for formatting and producing this report. Genuine gratitude goes to Ms. Maryam Sheikh, the Council's Programme Officer for FGM, for providing useful insights on the cultural perspectives of sexual violence in the Wajir community and to Mr. Erick Oweya who facilitated analysis of data collected. Special thanks go to Dr. Ian Askew and Dr. Jill Keesbury for guiding the project.

The study was an eye opener and an extraordinary learning experience. Heartfelt gratitude goes to all the women, men and youth who agreed to take time off their busy schedules, especially during the holy month of Ramadan, to participate in the study. Participation by key staff of the police, Ministry of Public Health and Sanitation, the Kenyan Judiciary, and the Kadhi court is gratefully acknowledged as are the contributions of the key informants from religious institutions, nongovernmental organizations and community based organizations in Wajir.

Finally, heartfelt appreciation goes towards CIDA-GESP who financially supported the project and made it realizable. 


\section{ABBREVIATIONS}

$\mathrm{CBO} \quad$ Community based organization

CIDA-GESP Canadian International Development Agency- Gender Equity Support Project

EC Emergency Contraception

FGD Focus Group Discussions

FGM Female Genital Mutilation

HIV Human Immune Deficiency Virus

GBV Gender Based Violence

IEC Information Education Communication

IPV Intimate Partner Violence

NCSI Nairobi-based Crime Scene Investigations

NEP North Eastern Province

NGO Non Governmental Organization

PEP Post Exposure Prophylaxis

SGBV Sexual and Gender Based Violence

SOV Survivor of Violence

SSA Sub Saharan Africa

STI Sexually Transmitted Infection

VAW Violence Against Women

VCT Voluntary Services and Testing

VOV Victim of Violence

WHO World Health Organization 


\section{TABLE OF CONTENTS}

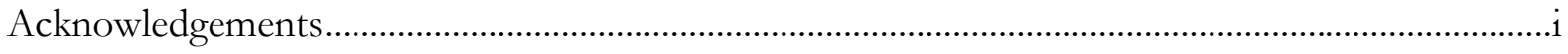

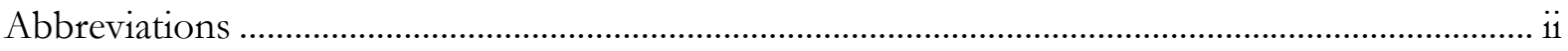

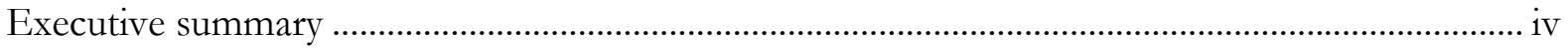

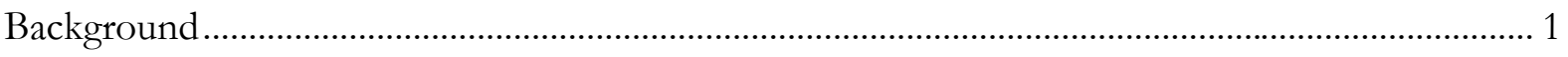

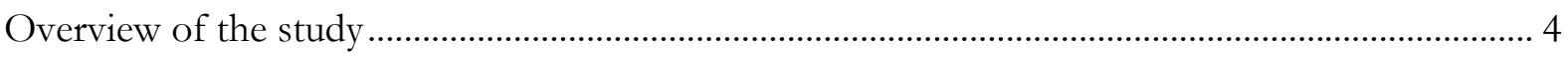

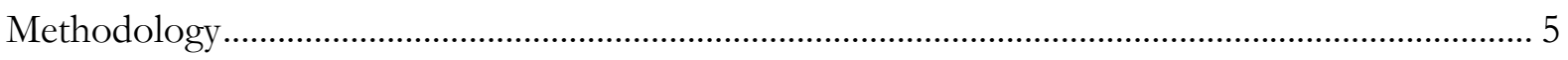

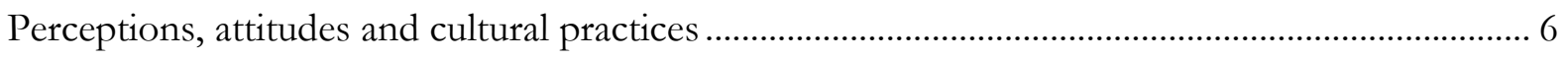

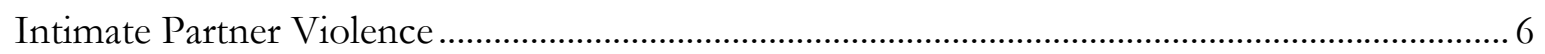

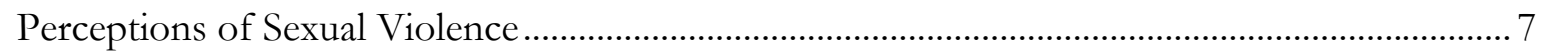

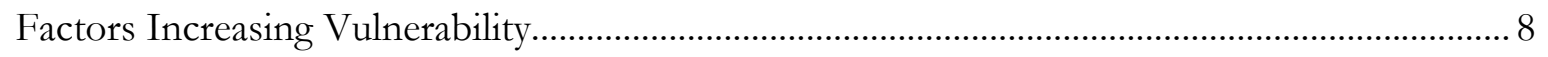

Dispute resolving mechanisms in the community ................................................................

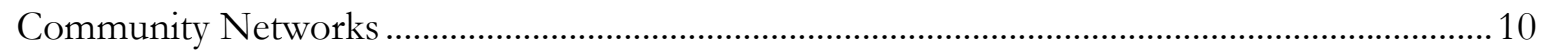

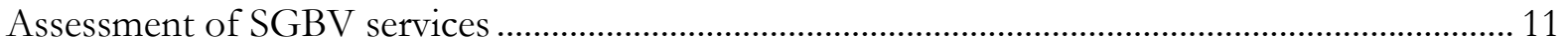

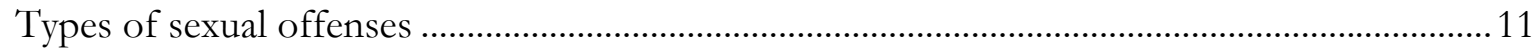

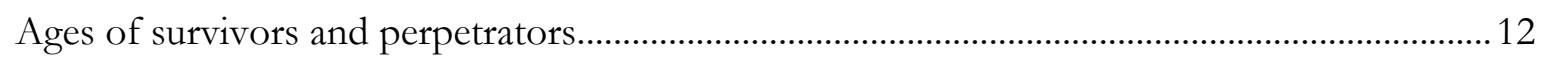

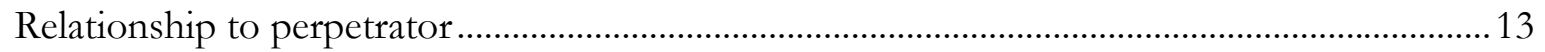

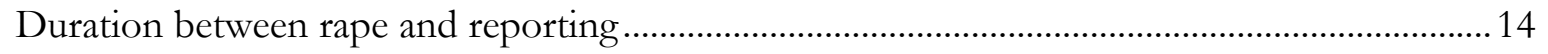

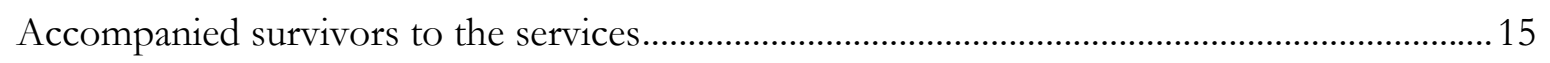

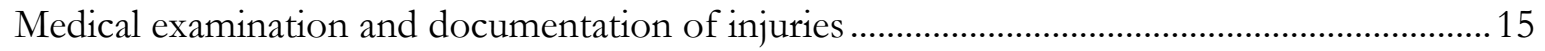

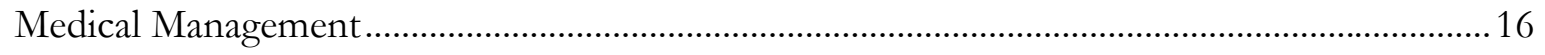

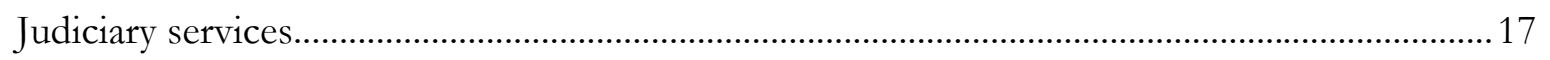

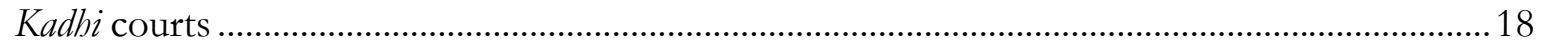

Current and preferred services for sexual violence .............................................................................. 19

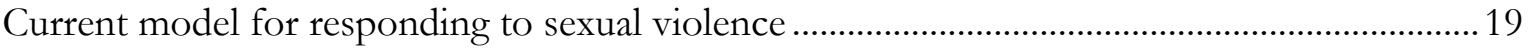

Recommended model for responding to SGBV in Wajir District..................................................20

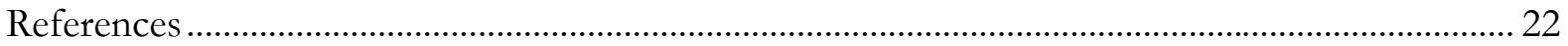




\section{EXECUTIVE SUMMARY}

A 2006 baseline survey conducted by CARE Kenya indicated that sexual and gender based violence (SGBV) is widespread throughout North Eastern Province. Other findings revealed that high levels of stigma and gender imbalances are associated with sexual violence and FGM and that a coordinated approach to responding to the service needs of survivors is missing. Moreover, there is limited awareness of the legal mechanisms available to survivors, including those beyond the traditional systems.

With financial support from the Canadian International Development Agency- Gender Equity Support Project (CIDA- GESP), Population Council undertook a study in Wajir District to ascertain the need for and possible components of an integrated and comprehensive services model that would be able meet the particular needs of survivors of sexual and gender based violence in the province.

The study confirmed that sexual violence is widespread in this primarily Somali community. Factors contributing to perpetuation of the violence are: cultural practices such as abduction and early child marriages; gender and cultural roles that discriminate girls' access to education; the community's interpretation of the appropriate age of marriage for a girl; housing arrangements that enable SGBV to occur; and inter-tribal conflicts, in which rape and acts of bestiality are committed for revenge. Unmarried girls between the ages of 9-15 years appear to be the most vulnerable because they spend most of their time in the bush herding goats.

Intimate partner violence (IPV), especially male to female spousal physical abuse, is also widespread. Male to female physical abuse often precedes sexual abuse within marriage; however, female to male spousal physical abuse was also reported and is thought to be on the increase. Almost universal, the practice of female genital mutilation (FGM), which can make sexual intercourse both difficult and painful, was suggested by women and youth as a possible reason for high levels of marital rape; moreover, marital rape is not viewed as a violation of women's rights. Some male to male sexual abuse was identified.

Women reported preferring to seek legal redress for marital issues (divorce and IPV) at the Kadbi court and to report rape and defilement cases to the police. Men on the other hand preferred the traditional courts (maslaha), which is commonly used among the Somali community to resolve disputes. However, many female respondents felt that judgments passed by these courts are usually unfair and biased in favour of men. Another issue of concern to the community, police and judiciary is that the maslaha system undermines the constitutional judicial system, although the police and Kenyan judiciary were also cited as potential barriers to justice for SGBV survivors.

The maslaha system settles disputes through compensation. For survivors of violence, the perpetrator is asked to pay a number of goats (usually about ten) or for replacement clothes (about Kshs 5,000 (\$80)) to the survivor's family. Punishment for raping a virgin girl is more severe than that of older or married women; perpetrators are ordered to pay more goats to the families of young survivors or even to marry them. The maslaha system works closely with the provincial administration - and specifically the Chief's Office - from which it derives its legitimacy. However, police, the judiciary and religious scholars and institutions interviewed were strongly opposed to sexual and capital offences being handled and arbitrated by the chief's and maslaha procedures because handling cases through these systems denies survivors access to medical, psycho-social services and legal redress. 
"....we the Council of Imams in Wajir, have agreed that ALL cases of rape, defilement and sodomy should be referred to police and subsequently the judiciary. We will ensure no cases of this nature are handled the maslaha way...." (Religious scholar).

Health workers and women interviewed said that FGM complicates the care and treatment of SGBV survivors. According to the police, FGM has sometimes been used to conceal evidence of defilement in girls. At the provincial general hospital, psycho-social care and support for survivors is provided in ad-hoc manner and is contextualized to HIV testing and post-exposure prophylaxis (PEP). Misconceptions regarding administration of the correct PEP dosage and the regimens to offer existed among health workers, with many nurses believing that PEP and STI prophylaxis is offered only once, as is the case with emergency contraception. Another challenge when filing complaints is that survivors are charged Kshs. 400 for the medical examination, which in most cases they are unable to pay.

Attrition rates of survivors from the hospital through to the police and judicial system is very high. The study indicated many fewer cases than were reported making it to the judiciary and even fewer convictions of perpetrators. Community respondents indicated a preference for an integrated model of care and support that could be incorporated into existing reproductive health or VCT services.

Also recommended was the need to train hospital, judicial and police staff in care and handling of survivors of sexual and domestic violence; the need for clear protocols for managing survivors was also expressed. Most women and female youth underscored the need for advocacy and lobbying for girls to be enrolled in school as a measure for preventing their physical and sexual abuse. Community led support groups to undertake referral and provide psycho-social care and support were noted as potentially useful.

Involvement of religious scholars in educating communities about the rights of women, from an Islamic perspective, was deemed important. This is because amongst the Somali, negative attitudes and perceptions towards women and the violation of their rights are often wrongfully justified as having an Islamic basis. The only way that this perspective could be corrected is by sensitizing the community about Islam's correct position on women's rights sexual violence. This could be done through IEC material development and capacity building of community organizations and religious leaders. 


\section{BACKGROUND}

"Violence against women must be addressed on multiple levels and in multiple sectors of society simultaneously, taking direction from local people on how women's rights may be promoted in a given context" (Executive summary, Report of the Special Rapporteur on Violence Against Women, ${ }^{1} 6$ January 2003).

There is no single or universal definition of gender-based or sexual violence. Understandings differ according to country, community and legal context. For instance, prevalent definitions of sexual violence often exclude children. The lack of a clear and commonly accepted language inhibits the development of an effective reporting system and/or databases, and thus restrains prevention, monitoring and advocacy efforts (Baker, 2007). The term sexual and gender based violence (SGBV), in its widest sense, refers to the physical, emotional or sexual abuse of a survivor. It connotes the use of physical violence or psychological pressure to compel a person to participate in a sexual act against their will, whether or not the sexual act is consummated.

This document adopts the inclusive terminology employed by the World Health Organization, which defines sexual violence as "any sexual act, attempt to obtain a sexual act, unwanted sexual comments or advances, or acts to traffic women's sexuality, using coercion, threats of harm or physical force, by any person regardless of relationship to the survivor, in any setting, including but not limited to home and work". The scope of the definition is here expanded to include forced sex, sexual coercion and rape of adult and adolescent women and men and child sexual abuse and includes a sexual act (whether attempted or consummated) involving a person who is incapable of understanding the nature or significance of the act, or of indicating his or her refusal to participate in the act, e.g. because of disability, or because of the effect of alcohol or other substances, or because of intimidation or pressure (WHO, 2003b; Saltzman et. al, 1999).

The term sexual violence is used to represent much behaviour that may otherwise fall under the rubrics of sexual abuse, sexual assault, and any other sexual violations, such as sexual harassment and voyeurism. The term gender-based violence is widely used as a synonym for violence against women, in order to highlight the gender inequality in which much violence is rooted (IGWG of USAID, 2006). However, while this review acknowledges that the overwhelming recipients of violence are female, the term gender-based violence is here used to encompass all women, men, girls and boys who have experienced sexual violence.

Social, economic, and gender issues are increasingly recognized as significant factors in countries of east and southern Africa that underlie the HIV epidemic, keep maternal mortality and fertility rates high, and increase the likelihood that sex will not be safe, voluntary, or pleasurable. Violence against women and children, of both sexes, has gained international recognition as a serious social and human rights concern affecting all societies. Epidemiological evidence shows that violence is a major cause of ill health among women and girls, as seen through death and disabilities due to injuries, and through increased vulnerability to a range of physical and mental health problems (Krug et al., 2002; Mugawe \& Powell, 2006). Female survivors of sexual violence not only sustain physical injuries, but are more likely than other women to have unintended pregnancies, report symptoms of reproductive tract infections, have multiple partners, and less likely to use condoms and other contraceptives (IPPF, 2004; Campbell \& Self, 2004). Violence, and the fear of violence, severely limits women's contribution to social and economic development, thereby hindering achievement of the Millennium Development Goals

${ }^{1}$ United Nations document E/CN.4/2003/75. 
and other national and international development goals. Rape and domestic violence account for $5-10 \%$ of healthy years lost by women (WHO, 2001). As described by the World Bank's Gender and Development Group, such violence can include, but is not limited to:

- Physical violence (slapping, kicking, hitting, or use of weapons).

- Emotional violence (systematic humiliation, controlling behaviour, degrading treatment, threats).

- Sexual violence (coerced sex, forced into sexual activities considered degrading or humiliating).

- Economic violence (restricting access to financial or other resources with the purpose of controlling a person).

Violence may be experienced at separate and multiple stages of the life cycle. However, many sub-Saharan African (SSA) countries lack systematic and reliable data on sexual and genderbased violence. There is need for systematic data collection on the prevalence and forms of SGBV in SSA, which would in turn inform the development of meaningful strategies.

Programme design is hampered by the absence of evidence driven, preventative or responsive interventions. The UN Secretary-General's report on violence against women includes valuable suggestions for the collection of data, and also highlights that programmatic areas that are currently under-researched, The United Nations General Assembly (UN-GA, 2006).

The overwhelming focus, in both research and programmatic interventions, is on researching and alleviating the impact of sexual violence on women. However, the majority of sexual abuse survivors presenting for services are usually children and not adult women who are the target group for whom most services are designed (WHO, 2001). Programme managers and policy makers continue to see adult women as the norm and modal group. There are limited examples of programmes that have explicitly sought to address the needs of children, males or other minority groups (such as the physically or mentally handicapped), rather than trying to serve them as an additional or special category. The following sections examine approaches to enabling presentation and managing cases of child and male survivors.

The link between SGBV and HIV \& AIDS cannot be ignored. HIV prevention, care and intervention programmes must include messages aimed at reducing sexual violence and coercion as a means of reducing HIV transmission. A statement provided (on behalf of the United States of America) at the UN General Assembly high level meeting on HIV/AIDS, held in June 2008, stated that:

"...we must target our support to the community level, empowering local people and the community-and faithbased organizations that best 'know their epidemic' - and know how to engage people in responding to local drivers of infection such as sexual coercion, violence and rape. Together we can push prevention to the next level and ensure that we begin the generational approaches that will lead to an HIV-Free Generation...." (Ambassador Mark Dybul, PEPFAR Coordinator, June 2008)

Like other countries in sub Saharan Africa, sexual violence is widespread in Kenya. However, it was only recently criminalized through enactment of the Sexual Offences Act in 2006. This law, which is still being reviewed, contains 14 offences and also criminalizes sexual harassment. SGBV exposes survivors to the risk of contracting HIV, the prevalence of which in Kenya is about seven percent. The Ministry of Health has guidelines for the medical management of survivors of sexual assault, which includes treatment for sexually transmitted infections, counselling for HIV testing, and, if HIV-negative, post-exposure prophylaxis (PEP) for HIV (including PEP adherence counselling). Unfortunately, this care is not available to many Kenyans. 
According to an observational study conducted by the NGO Liverpool VCT, in three post rape care clinics, $29 \%$ of women reported having experienced sexual violence in 2006 . Between November 2003 and June 2005, a total of 295 survivors of sexual assault were seen. The majority $(89 \%)$ were female and most were very young - the median age was 16.5 years. More than half (56\%) were children; the youngest survivor was 16 months old and the oldest was 102 years. One in seven (14\%) of the survivors did not present to the hospital within 72 hours of their assault and were, therefore, not eligible for PEP. There is very little awareness, very little information, very little knowledge about PEP following sexual trauma in Kenya, and efforts should be made to increase awareness Also, while nearly everyone who was eligible for PEP began the medication, they were much more likely to successfully complete the full course if given relevant counselling.

According to a female respondent, rape and defilement cases are on the increase after the December elections in Kenya. "...clans of MPs who lost during last year's general elections are retaliating by sexually and physically assaulting young women and girls..."

In responding to the growing awareness of the link between sexual violence and the spread of HIV \& AIDS, the Ministry of Health has taken a proactive role to address sexual violence. Through several units and partnerships with various professional and civil stakeholders, it has facilitated the development and approval of the following policy guidelines for the effective administration of PEP for survivors of sexual violence. However, most of these guidelines and protocols are not followed in most hospitals or health centres in resource poor settings. These include:

The National Guidelines for the Management of Rape and Sexual Violence (2005). The Ministry of Health recommends the use of duo therapy where 2 different drugs zidovine- $300 \mathrm{mg} \&$ lamuvidine- 150 $\mathrm{mg}$ are recommended for all survivors of sexual violence. It also allows for consideration of triple therapy in cases of very high risks such as those involving gang rape.

The Rape /Sexual violence trauma counselling algorithm articulated in the national guidelines on medical management of rape and sexual violence details processes for catering for the psychosocial needs of survivors of sexual violence in relation to counselling and referral for medical care, reporting for future legal redress and preservation of evidence. The psychological aspects of counselling around HIV testing and compliance with the PEP regimen are included in this protocol. The counselling includes trauma crisis management to assist the survivor to cope with psychological aspects of sexual violence. It prepares survivor to take HIV test to know their HIV status and is instrumental for PEP adherence and pregnancy prevention.

The Kenya National Aids Strategic Plan (KNASP) 2005-2011of the National AIDS Control Council identifies survivors of sexual violence as a vulnerable group needing protection. It highlights the need for programmes to address this reality. The plan intends to strengthen the capacity of the police and health care system, including the private sector, to provide prompt services to survivors of rape and sexual violence including the provision of Post Exposure Prophylaxis services.

The Division of Reproductive Health in the Ministry of Health, together with other partners, has developed training manuals for clinicians and trauma counsellors on management of survivors of sexual violence. Post Exposure Prophylaxis features prominently as an imperative component of emergency care. 


\section{OVERVIEW OF THE STUDY}

This assessment was conducted in Wajir district in North Eastern Province to document and describe existing systems that respond to the needs of survivors of SGBV. It also describes the perceptions, attitudes and practices that exist in communities to respond to sexual violence. Information was gathered from the police, health workers, social workers, religious leaders, NGOs, CBOs and members of the community. These were targeted as being the first points of contact for survivors of sexual violence. The study established the type of services offered, how survivors are handled, what support is required form government, what linkages existed and will be needed.

The community's perceptions, attitudes and practices around sexual violence were also assessed. Prior to undertaking the exercise, a one-day 'buy-in' meeting was held with local leaders and stakeholders. The purpose of this meeting was to introduce the project, its aims and obtain support of local leaders, to engage with community members and service providers in the area.

The study also highlighted recommendations from various groups interviewed on how services for SGBV survivors could be strengthened in a socially conservative culture as that of the Somali living in the province. These recommendations are in form of gaps identified in the current response services for sexual violence. The study also teased out components of a comprehensive framework identified by both community and service providers. It is anticipated that these recommendations will feed into the national and provincial processes underway that seek to improve services for SGBV survivors. The project also provides concrete evidence to advocate for policies on response and access to services by survivors of sexual and intimate partners.

In summary the study aimed to:

- Assess cultural beliefs, behaviours and practices concerning SGBV in the Wajir District of NEP.

- Document current and preferred medical, psychosocial and legal responses by the Government of Kenya's health, police and social service sectors, as well as NGOs operating in the district.

Outcomes of the study include:

1. Description of cultural beliefs and practices concerning SGBV among the population living in Wajir.

2. Description of services preferred for the types and configurations of services that could be provided through government and NGO sectors.

3. Systematic documentation of the nature and quality of existing medical, psychosocial and police / legal services available for SGBV survivors in Wajir district.

4. Illustration of interaction of existing services in provision of support.

5. Overview of opportunities for increasing integration of services for enabling a more comprehensive response.

6. Community assessment geared towards determining how SGBV is defined culturally, including the types of violence that would be included and excluded from such a definition. 
The following activities were implemented to achieve these outcomes:

- Stakeholders buy-in workshop.

- Interviews with key informants, including police, health workers, judiciary, religious leaders and community.

- Focus group discussions with youth (male and female), service providers, religious leaders and elderly men and elderly women.

- Records review of services available at hospital, police, judiciary and Kadhi courts.

- Workshop to disseminate research findings to policy makers at national level.

- Workshops with community to agree on proposed model.

\section{Methodology}

Data collection and sampling was organized as follows:

A total of 13 in-depth interviews were conducted with influential people in the community, including religious leaders, opinion leaders and women's group leaders. NGO workers considered to be contact points for survivors of sexual violence were also interviewed.

Focus group discussions (FGDs) were conducted with representatives of population sub-groups to glean their different perspectives. These groups included middle aged married men and women, unmarried men and women, elderly men and women, divorced women, religious leaders, CBO and NGO representatives and Government officials. A total of 12 FGDs were conducted, at least one FGD for each sub-group. FGDs comprised of five to 11 respondents. Verbal consent was sought to interview all participants and none of the respondents were below 18 years of age. Local research assistants were trained in conducting interviews and group discussions. They also assisted to translate questions into the Somali language. All focus group discussions done in the community were conducted in Somali.

Facility record reviews: An assessment of existing services available at health clinics, NGOs, police, Kadhi court and judiciary was conducted by reviewing records kept at each institution. The records review sought to assess institutional and staff capacities to respond to sexual and intimate partner violence at the district hospital, police, Kadhi court and Judiciary in Wajir. Data obtained at the institutional level revealed patterns and trends in accessing services and justice. 372 sexual violence cases were reviewed in the four institutions mentioned for the period $1^{\text {st }}$ January 2005 to $31^{\text {st }}$ December 2007.

Prior to data collection, tools were developed and tested, which derived largely from the WHO tools for researching sexual violence. To design data collection tools for the judiciary, court records were perused and staff working there interviewed to establish the type of data most likely to emerge from the records. Data from the Kadhi court was collected by a staff member working there, which included a summary of the different types of cases handled at the court. At the hospital, a review sheet was designed to collect data as outlined in the ministry's Post Rape Care (PRC) form, which is used to record information about the sexual assault. 


\section{PERCEPTIONS, ATTITUDES AND CULTURAL PRACTICES}

It is important to note the community appreciated that sex is not always forced or coerced and that it can be consensual, pleasurable and mutually satisfying. Among the Somali community several terminologies are used to define and describe sexual violence. These include the following:

- Dabaxad and Mingal. A man quietly sneaks into a married woman's house and forces her to have sex without her consent.

- Xogitan or Xogis. Use of force by a man to have sex with a woman without her consent.

- Kufsin. Hitting the woman from behind using an object and then violating her sexually.

- Faraxumees and Mararid. Rape and defilement of young virgin girls. Literal translation is that, one has spoiled a girl's clothes with semen and removed the girl's clothes.

- Bojin. Refers to abduction of women during inter-clan conflicts and forcing them to marry.

- Qanis are terms referring to sodomy (of males) in the local language.

Other acts that constitute sexual violence include inappropriate touching and sexual harassment. These are also punishable in the community. "there so many things we can call sexual violence, for example, rape, physical touch like touching a girls breast and if it happens in this community they buy her a new dress for touching her"'(Community opinion leader).

\section{Intimate Partner Violence}

Marital rape is a common problem in the community but is perceived differently by men and women. "Ifyou look at our community, 80 percent of what happens is marital rape because a man believes that sex is his right and he can have it any time he wants. He doesn't care if the lady is prepared or not because he believes it is his and that is why there is a high number of divorces" (Women leader, Wajir).

If a woman complains, elders discourage her. "We have heard of such cases and this mostly happens when there is a misunderstanding between the couple and when the busband asks for his conjugal right and the woman refuses be ends up using force. It does happen but we usually tell the woman to persevere as she is married to serve her busband and we usually tell them to attend to their husbands unless they have just given birth or they have their periods" (Community elder).

Some women alluded that FGM makes them shy away from wanting to have sex because it is usually painful. This makes some of their partners physically and sexually abusive. Also, there have been instances where men have used knives to cut a woman's genitals when they failed to consummate the marriage on their wedding night.

"... Most of us Somali women go through pharaonic circumcision. Most of the times we don't have great desire for sex and when your husband comes and you say no, he beats you and forces you to have sex... it happens among many of us..."Young married female youth.

According to male religious leaders, there is nothing called marital rape because "...the woman has instruction from God to serve the man at all times....."

One female religious scholar expressed a different opinion: "... I think it is a bad thing since our religion does not allow for it. It is even in the Quran which says "I placed blessing between a man and his wife, therefore they should enjoy" (Female religious leader). 
According to Islamic principles, couples are forbidden to have sex when the wife is on her menses or bleeding after delivery of a baby. Demands for anal sex by husbands at all times are sufficient grounds for a woman to request for divorce, which will be granted. This was supported by a female religious leader in Wajir who said that, "according to our religion sexual violence is "baram" meaning its illegal for example people who are married there is an ayah [verse] in the Quran which says "there is some places that a man cannot use his wife-like having sex from behind."

"... for example, there is a case we received whereby a wife came complaining about her husband and we asked her what the problem was. She told us that her husband wanted to sleep with her during her periods and when she informed him that she was not clean he told her he will use the back side. In such cases they can be allowed to divorce and if the wife has children and she comes to the office complaining, we look at the busband. If he is a civil servant we deduct a certain amount of money from his salary and if he is not there are ways of dealing with him" (Religious leader).

Both young and older women noted that arranged marriages by parents, and which are not consented to by women, may also contribute to intimate partner violence and subsequent divorce in this community. "Forced marriages, whereby most of the time the girl is forced to marry the guy, and after living together for a while they see that it can't work and they get divorced."'(Middle aged women FGD respondent).

A similar sentiment was expressed by a female religious leader "The little I can say about early marriages or forced marriage. Most of the time it is the girl who is against the marriage because of being a tender age, for example, you can see a class five pupil given to a man for marriage and may be the person getting married to the girl is not someone responsible which can lead to divorce".

While both men and women agree that sexual violence is a crime, their perceptions about intimate partner violence (IPV) differ. Women feel that it is a violation of their rights while men perceive it as a private affair to be dealt in the confines of the family. Women prefer to report cases of IPV to the Kadbi court, while men prefer to go to the maslaba.

"... women have learnt that they can get their rights from the Kadhi court and so they will report domestic violence there... sexual and violence should be reported to the police" (Female respondent).

"... When a man fights in the house, no one needs to interfere. No one will ever know what is causing the fight. These things should be handled at home..." (Male respondents).

\section{Perceptions of Sexual Violence}

Shame and stigma associated with sexual violence, fuelled by cultural stereotypes, prevent women, girls and their families from reporting rape and defilement. A girl or a woman who has been raped will shy away from reporting because, the perpetrator can argue, through commonly used sayings, that the woman was willing and to imply that she is "loose". For example, men may justify their actions by arguing that "... I just fetched water where everyone does" (Female respondent), which connotes that the victim of rape is immoral and not a virgin.

Most families will therefore not dare to go public unless they can prove beyond reasonable doubt that rape actually took place. Another saying commonly used is "dhiibata dhiig malaha", which means "she who gives willingly has no blood money", which literally translated means that if a woman cannot prove that she was raped then she consented to the sexual act and is not eligible for compensation.

Survivors of sexual violence are often discriminated against. To guard against this, mothers ask their daughters who have been raped whether they were seen by any one. If it was not observed, they hide it from the general public as knowledge of the rape could reduce their future marriage 
prospects. "She can stay unmarried for quite some time but in the long run she ends up getting married and in most cases they end up getting old men who the other young girls have refused to marry". (Community elder)

Most women interviewed strongly opposed the notion that a woman can invoke rape whereas most men felt that women do invite rape if they dress provocatively and wear seductive perfume. If they do this then they are should be blamed for rape.

"In this community, we believe that if a problem happens at night between a man and woman then the woman is to blame..... Therefore there is time that women ask for sexual assault" (Community elder).

The majority of those interviewed denied that sodomy exists in Wajir. It is viewed as an abnormal act performed by abnormal people who are non Somalis. "I have heard of an insane man who had sexual affair with another man" (Middle aged women FGD, respondent). While responding on incidences of sodomy, religious leaders said that it was unheard of. "I have never had sexual violence involving men and boys in this community but sexual violence of women and girls are there in this community". Another religious leader responded, "sexual violence involving women and girls are common but other forms may be possible in this community as we are all human beings", and the third added, "there are sexual violence involving men, women, boys and girls in this community. "A man was arrested for sodomizing two boys...", but community members considered the assailant mad. "I have heard one case in Habaswein involving a person from down Kenya (assailant) and a berd's boy (victim)..... There was one case reported in this town involving a man of Arab origin who sells drugs" (Religious leader, Wajir).

\section{Factors Increasing Vulnerability}

Places where miraa (khat) is sold and chewed were viewed as extremely unsafe. Female youth were categorical about not wanting to be around these places after dark. Women also said that they felt unsafe during inter-clan conflicts and rivalry. Bar maids are also susceptible to sexual violence, as in many communities. According to the police, they are usually attacked by their patrons, usually on their way home from work. Adult women (usually divorcees), who sell tea to miraa chewing men are also targeted for sexual violence.

Divorced women, referred to as "garooba", are another target for sexual and physical violence. Violence is sometimes meted out by their ex-husbands and yet the majority suffer in silence. Because it has been their choice to end or walk out of an unhappy marriage, they are regarded as outcasts and so vulnerable to assault.

".... Untilyou came today, I did not know that what my ex-busband does to me is wrong. I ended the marriage because be refused to provide for the children. He still doesn't but he comes to my house even if I know he is married to someone else... he threatens me and says I must sleep with him because his wife is pregnant or on her periods. Even if I refuse he still forces himself on me" (Female divorcee).

Young girls aged between 10 to 15 years are considered the most vulnerable to sexual violence. These girls are marginalized and not given equal opportunities for education as their boy-child counterparts. While majority of the boys go school, girls are sent to the bush to herd goats, where they are highly vulnerable to perpetrators, usually older men.

"Rape... it is common in Somali culture especially those in the bush. Eighty percent of the victims are girls who look after goats in the bush" (Woman leader and head of a local CBO).

Other factors perpetuating sexual violence in Wajir are drug abuse and poor housing. Miraa (khat), kuber (powdered drug) and bhang (Marijuana) are common drugs taken by male youth and some older men and can increase the likelihood of perpetrators raping women and girls when they are high. Insecure housing is another key contributor to sexual violence in this community. Normally the traditional Somali hut (heriyo) does not have a secure door, but instead has only a 
piece of cloth that covers the entrance. This facilitates mingal and dabaxad, increasing the chances of women being raped in their homes when their husbands are away seeking pastures. It is difficult for women to raise the alarm when this happens and proving whether sex was consensual or not.

Most men interviewed did not view mingal as a violation. They argued that "somehow" consent was given by the women in the process, because women do not scream. Women argued that victims comply with rapists because they do not want to get hurt, especially in circumstances where weapons are used to threaten them. Also fears of being shamed and stigmatized prevent women from raising alarm.

\section{Dispute resolving mechanisms in the community}

"When faced with problems, both men and women go to the community elders. They all go to the community elders, and if they fail to solve the problem it is taken to the area chief. If he fails he forwards to the court or to the Kadhi court. Depending on the nature of the problem some are solved at family level by parents or relatives" (Religious leader FGD).

Most sexual violence cases are settled outside the formal legal system. Out of 87 cases of sexual offence reported at the hospital, 35 of these were taken to court. One case related to bestiality, four of these never reached the first hearing due to withdrawal by the complainant and seven files were missing, which could mean that almost half of sexual offences committed in the community are settled through other means besides the court. Traditional methods are preferred because of compensation, which is also wrongly interpreted as having a basis in Islam. These misconceptions are spread within the community by some religious leaders.

"Islam has provided a solution for survivors of sexual violence in the Shariah law. Unfortunately we cannot implement it in a secular state, the Kadhi's court has no power to deal with sexual violence cases and it only deals with inheritance and marriage issues. The secular court at most punishes the offender but does not compensate the survivor denying her rights" (Religious leader).

"In Islamic law sexual violence is defined having sex with the opposite partner outside marriage with or without consent. Rape is also considered sexual violence in Islam. If a married woman who is not a virgin is raped she will be compensated money equivalent to her dowry for the humiliation. If the survivor was a virgin she will also get money equivalent to dowry and at the same time she will be compensated for losing her virginity. This is at the discretion of the Kadhi's court. The punishment for rape and sodomy depends on whether the assailant is married or not. If he is married and commits the offence he will be stoned to death and if he is not married he gets 100 strokes of the cane" (Religious leader, FGD respondent).

Punishment for rape and defilement varies depending on the nature of sexual assault and the age of the survivor. If a man touches a girl inappropriately, he is ordered to buy her new clothes. Defilement attracts a more severe punishment. The perpetrator is fined and ordered to pay a number of goats, money or new clothes to survivor. He can also be caned. Punishment for rape of married women and widows is less severe. Rape of divorced women is not taken seriously.

"...we call for an emergency meeting and let the community know of the incident. We bring the perpetrator and mostly we fine bim and he ends up paying 10 goats and about Kshs. 5,000 to buy new clothes for the lady. The person who defiles a young girl is severely punished while it is a little bit lighter when it comes to rape of a woman. The one who defiles a young girl is not only fined a buge amount of animals but is also tied up and beaten thoroughly while the one who rapes a married woman is only fined. We take them far away from the homestead and his feet are properly caned. This is because the young girls have lost a lot, for example, their virginity unlike the old married or divorced woman who has already lost it, as in the Somali community virginity is highly valued" (Community elder). 
The elder explained further that the person is punished according to the severity of the case and he gave an example whereby a man raped a married woman herding camels: "There was this lady who was taking her camels back home from grazing. She was married and a man raped her. What we did as elders, we fined him 10 goats for raping the woman and 20 goats for making the camels run away" (Community Elder).

Court procedures can prevent the community from seeking formal legal redress, according to one female respondent: "Most of them don't go to the court because of the nature of questions asked, which is very difficult to answer, for example, how long was the thing and when the girl keeps quiet the court is adjourned. I am speaking of a case I witnessed" (FGD Wajir peace committee).

Community elders noted that they lost confidence in the government judicial system, which they felt was highly compromised at times, making them revert to their traditional dispute resolving methods.

"Previously, as a community, we resolved that all rape cases would be dealt with by the court of law. But we were not satisfied with the judgments at the court and this has made us change our minds and revert to our old ways of solving problems of rape, where if a man rapes a girl who is below the age of 18 years he pays 10 cows and then marries the girl. If he refuses to marry the girl then he pays 15 cows as compensation" (Elderly Men, FGD).

The area chief has given community elders the mandate to arbitrate over sexual assault cases through maslaba. Cases are only reported if consensus is not reached. When this happens, he hands the case over to the police, which is usually way past the 72 hour window period for medical management. Many women are opposed to rape and defilement cases handled at maslaha: "We want them to be arrested and taken to the police. What do you think the elders can do for you?" (Elderly women, FGD).

\section{Community Networks}

There exists no functional network to respond to the needs of survivors of sexual violence in Wajir. Organizations such as Maendeleo ya Wanawake, Wajir Pastoral Women, Wajir Peace Committee, Wajir Women for Peace, Wajir Human Rights Watch and the governmental Kenya National Commission on Human Rights (KNHCR) are involved in advocacy for women's rights and SGBV, but due to their limited capacities and a lack of linkages to existing services, responses to sexual violence cases are not effective.

These organizations work independently in an ad-hoc manner and their efforts are not coordinated and structured. The KNHCR gives legal advice to survivors by partnering with pro bono lawyers in Nairobi who give survivors legal representation if they are willing to pursue justice. KNHCR also refers cases to the police if they had not reported to the police first. "They come to us we also give them legal guidance. We advice the parents to report cases to the police because they don't really understand what happened to the girl and encourage them to pursue the matter with the police" (Human Rights officer in Wajir).

According to the Commission's representative, the biggest challenge in dealing with sexual or IPV cases occurs when they are first reported to the traditional courts and they only get to the Commission after a long time has elapsed, sometimes after one year when the evidence has been lost. "The traditional system rules that the man compensates the woman for raping her and then marries her. When the man fails in his responsibilities then they report to the commission that they were raped and they need help and we are not able to assist them for lack of evidence. The police also can't help where evidence has been destroyed". (KNHCR Respondent). 
Other organizations, like Maendeleo ya Wanawake, train the community on legal issues concerning rape and that any matter concerning rape should not be dealt with through the maslaha. They also referred to a case they pursued successfully and the rape assailant involved was jailed for about 15 years.

The Pastoralist Women organization, an advocacy group, is setting up local level partnerships between pastoral communities, civil society, private sector, media, donors and government so as to make basic rights a reality for the pastoral women and girls. It is also advocating for institutional reforms that create space for women's participation in decision-making forums and processes. They advocate for the rights of women and fair access to the justice system. They also lobby for girls and women to have access to basic services like health, water and education.

\section{ASSESSMENT OF SGBV SERVICES}

Record review sheets were used to extract quantitative data from the police station, health facilities, the Kadhi court, and judiciary institutions. At the Wajir law courts, 57 cases reported over the three year period were assessed. Out of these, 50 files were retrieved and seven were said to have been referred to the court of appeal in Nairobi. The police department recorded 44 cases of sexual offences, but only 37 files were retrieved. This could be attributed to lack of a proper filing system for documenting and recording assault. Files are stored at the police registry and are placed together with all other offenses. One has to sift through all the files to separate those related to sexual violence. Sources of data at the police department included the occurrence book, crime register and criminal or case files that contain statements by the survivor, witnesses and the assailant.

Records reviewed at the hospital totalled 87 , but only 57 were taken to court, implying that a substantial number of rape cases managed medically do not reach the judiciary. At the Wajir

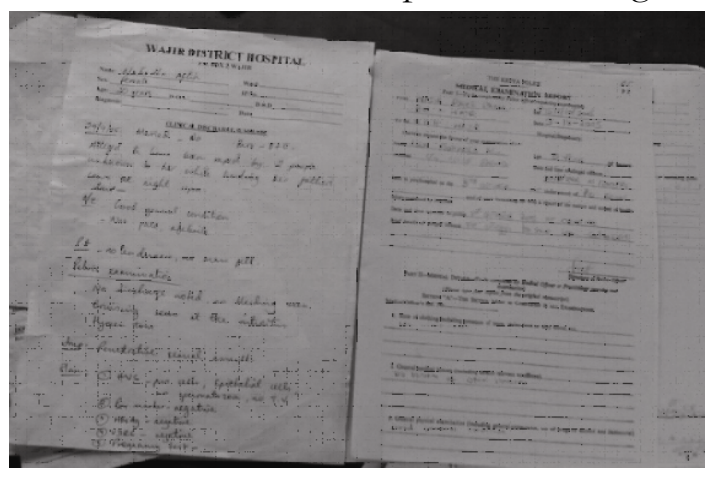
District hospital, there is no specific rape register, but the filing system was far more organized than at the police station. Copies of the police P3 forms were used as well as the hospital registry and occasional patient notes (see photo). All the 87 forms were filled, reviewed and signed by a doctor, implying that a large number of survivors did not go to the police for legal redress after treatment. Some forms were missing certain information and so the data analyzed did not always total 87.

\section{Types of sexual offenses}

Types of assault identified include rape, sodomy, and defilement of a minor, incest, and unnatural offences (referring to anal sex). Distribution of these types of offences by type of institution is given in the graph below. Although cases of incest were reported at the judiciary and police, none were reported at the hospital, which may reflect which information is collected by different institutions. At the hospital, the age of the survivor is recorded but not the relationship between the perpetrator and survivor. On the other hand, the police record the relationship of the perpetrator and survivor in order to define legally whether the offence is rape or defilement. 


\section{Types of offences reported}

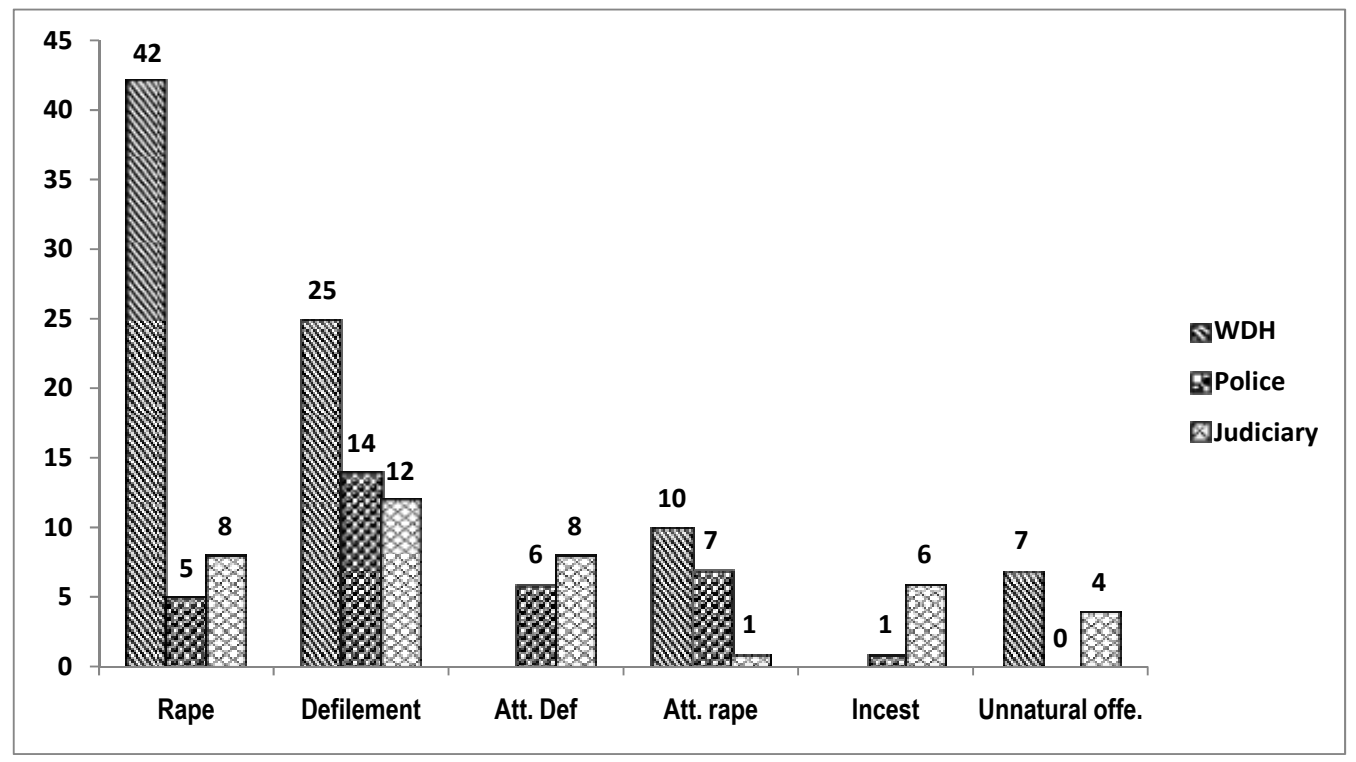

At the hospital, all eight cases categorized as unnatural sexual offenses were identified as sodomy, but none of these were identified at the police station because some of the files were missing. However, at the judiciary, sodomy is classified as an unnatural sexual offence and is grouped together with bestiality and it was therefore not possible to establish how many cases of each. This could probably be associated with the stigma faced by men and boys experiencing sexual violence, who will probably seek medical services without pursuing legal redress.

\section{Ages of survivors and perpetrators}

The ages of survivors ranged between three and 84 years. At the hospital the vast majority (83\%) were aged five to 20 years, with almost one half (38/84) below 15 years and over one third (31/84) between 16 and 20 years old; this is similar to the age distribution found at the judiciary (37/41 or $90 \%$ ). Perpetrators of sexual assault are also generally young men below the age of 20 , as can be seen in the graph below that shows records from the judiciary

\section{Age of perpetrators (judicial records: $\mathbf{N}=22$ )}

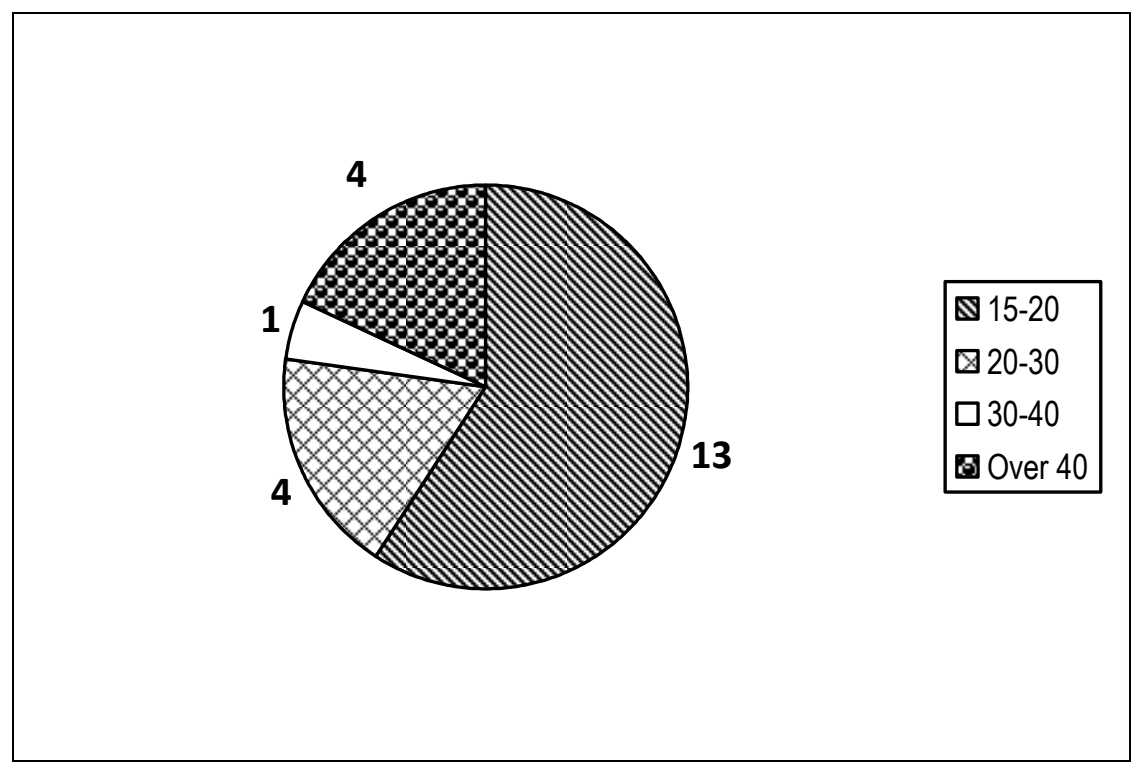




\section{Relationship to perpetrator}

Findings from this study supported those from many studies in other settings as the perpetrators of sexual violence were usually known to the survivor. At the hospital, records indicated that 73 of 75 of survivors knew the perpetrator, although lower proportions were found at the police station (22/33) and the judiciary (21/43), which may reflect a reluctance to pursue prosecution against known perpetrators. Perpetrators are usually neighbours, with smaller proportions being relatives, boyfriends or husbands (see graph below).

\section{Relationship of the perpetrator to the survivor when recorded}

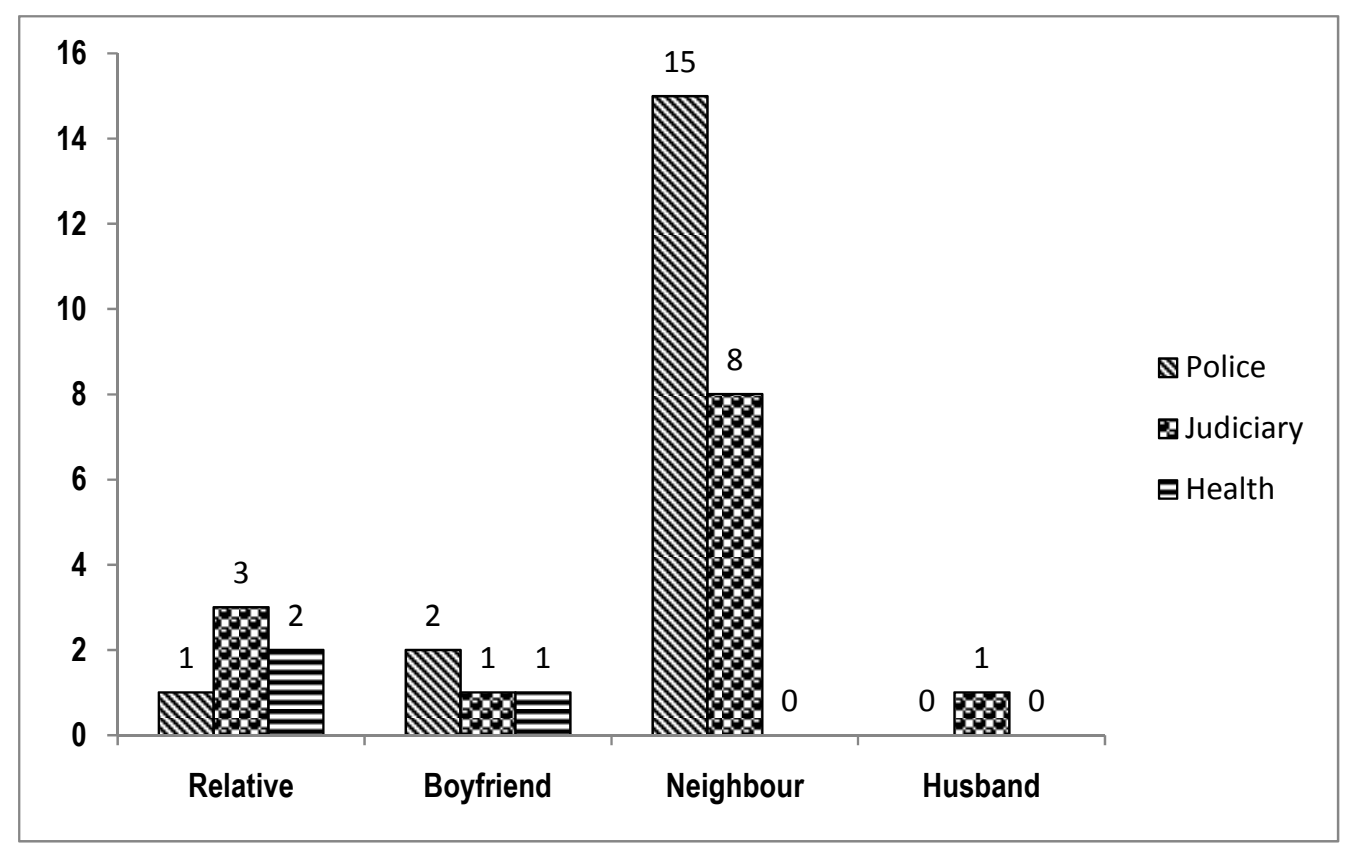

\section{Place and time of the assault}

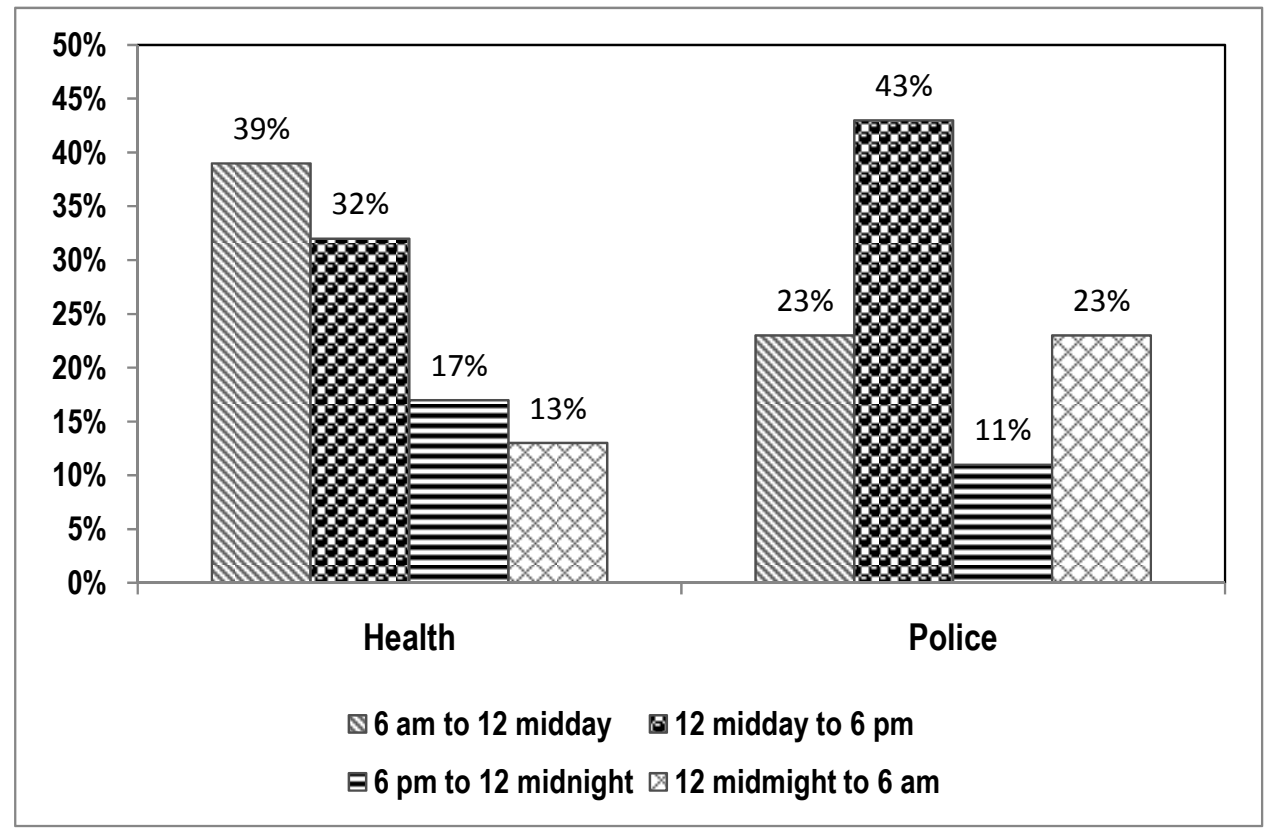


According to police and hospital records, most offences (71\% and $66 \%$ respectively) occur in the daytime between $6 \mathrm{am}$ and $6 \mathrm{pm}$. Police and court records noted that sexual assault frequently occurred in the bush and at the person's home, due to their vulnerability when goat herding or when the husband / father is travelling away from the home. Environmental factors, such as drought or the rainy season, are thought to contribute to sexual violence. During droughts, men travel long distances away from home in search of pastures for their camels and may defile girls and women they meet when travelling. During the rainy season, when there is less hardship and food and milk are available, young men eat well and, according to elders, are more sexually motivated.

"It mostly happens between $10 \mathrm{am}-1$ pm when the young girls have gone to look after the goats and they are alone.... that these things happen and during the rainy season when young men are sexually active as there is a lot of milk and most of them are idle"(Community elder).

This perception was supported by the magistrate of the district court; "defilement is common, because of cultural practices. Girls aged between 6 and 7 are ones who look after goats and on many occasions they need to go far away from home into the bush to look for pastures, which are very rare in this region. There they meet men who are in bush and these ones are the ones who herd camels and have not met their wives for long time therefore they rape young girls" (Magistrate, Wajir).

Inter clan fighting appears also to increase incidences of sexual violence. During these conflicts, rival clans use rape of women and girls as a weapon of war.

\section{Place of Assault}

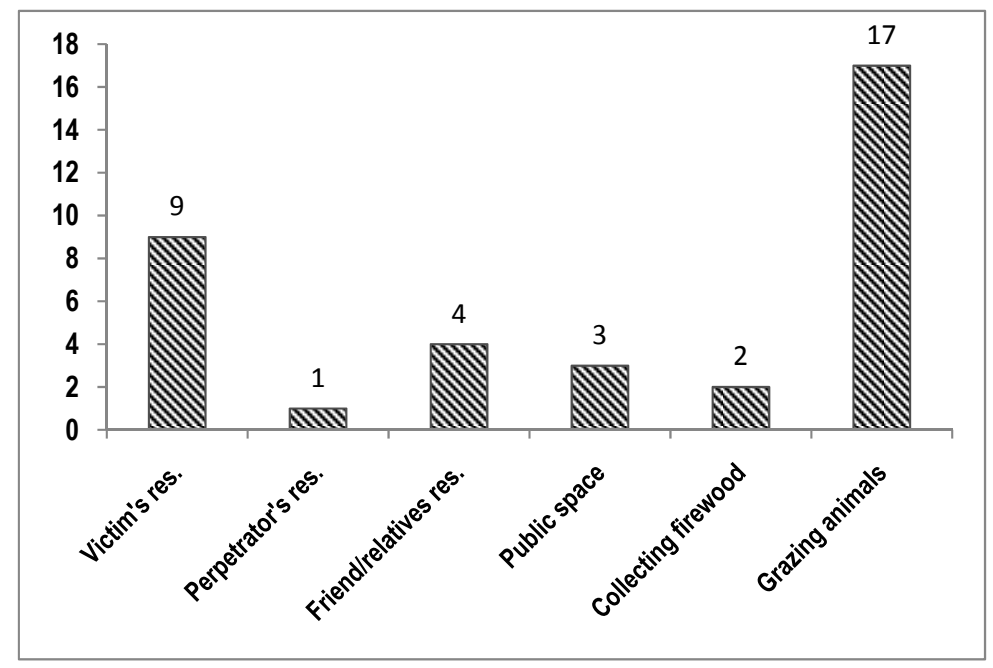

Place of sexual assault; $N=35$

Police records indicated that the common places for sexual assault are in the bush when girls are grazing animals $(17 / 35)$ and the victim's residence $9 / 35$.

\section{Duration between rape and reporting}

Most survivors report to the police before they go for medical treatment at the hospital, suggesting that communities may perceive rape and defilement as primarily a criminal concern. According to hospital records, 53 out of $69(77 \%)$ cases treated were reported to the police within 72 hours, whereas $42 / 74(57 \%)$ were reported to the health facility within the same period. Delays in reporting could be attributed to the vastness of the district, which reduces proximity to a health facility -39 percent of survivors travelled over 10 kilometres to reach the district hospital or the police station. 


\section{Duration between sexual assault and reporting to the police and health facility}

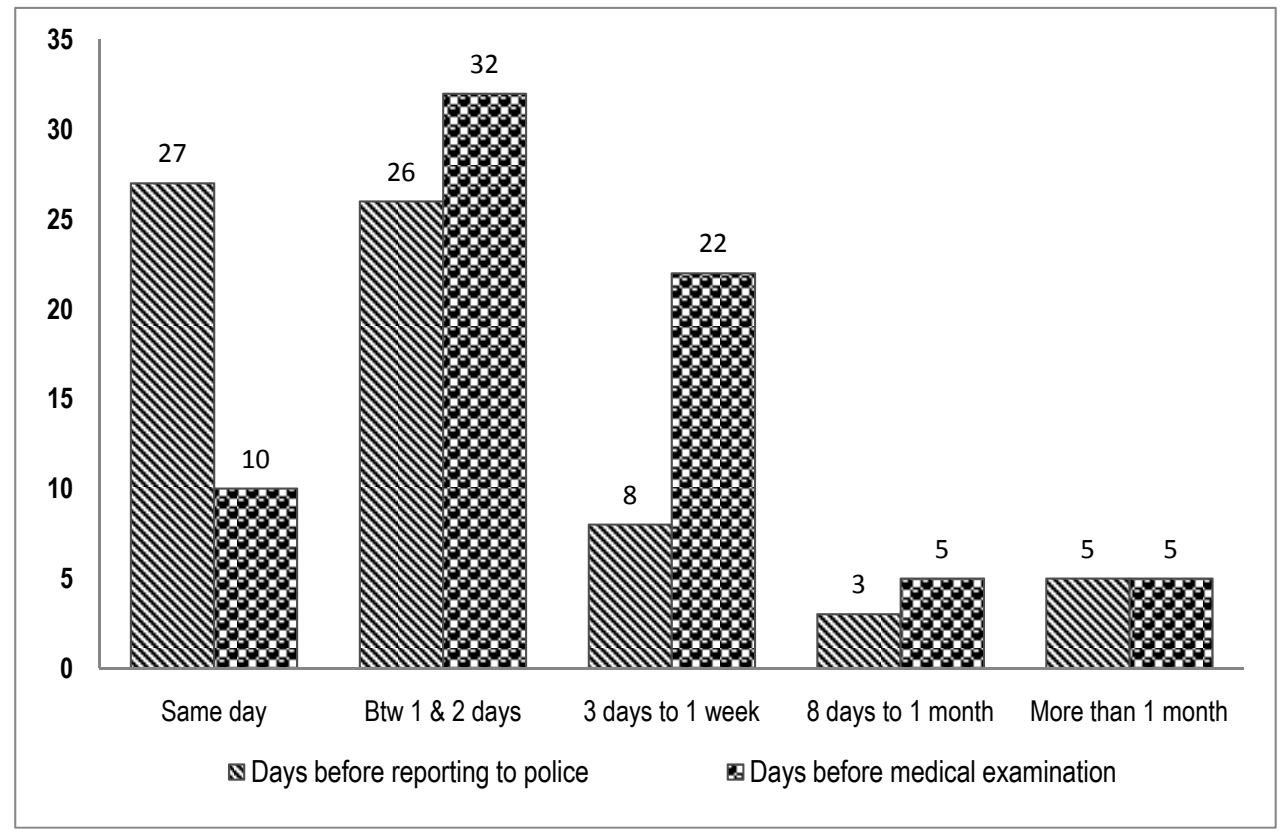

\section{Accompanied survivors to the services}

Whereas police officers usually accompanied survivors who reported to the police station to the health facility, of the 36 survivors that went from the health facility to the police station, 15 were accompanied by parents, 14 by relatives, 2 were unaccompanied and in five cases the police came to accompany them.

The police issued P3 forms to all survivors free of charge and referred all cases to Wajir district hospital for treatment, medical examination and completion of the P3 form to provide forensic evidence. At the hospital examination for completion of the P3 form is reported to cost Kshs. 400 , which is confirmed by the health personnel at the health facility. This fee is too expensive for the majority of survivors resulting in them preferring to use the maslaha system.

\section{Medical examination and documentation of injuries}

The district hospital did not have a rape register or copies of the Ministry's Post Rape Care (PRC1) forms. The PRC form has been approved by the MOH to document sexual assault injuries, and can be used as forensic evidence for criminal prosecutions. Whether the survivor changed clothes or not was documented in only 23 of the 87 cases seen in Wajir District Hospital and in three cases clothes were taken as evidence of the assault. Clothes can be an important source of evidence from a survivor but they are not readily available as survivors tend to wash, change or destroy them, as they are not aware of their role as evidence.

".. Girls change the clothes which have the evidence and sometimes wash them, and the girl takes a bath and this makes our evidence not to be concrete" (police officers FGD).

Even where clothes were taken as evidence, details about who was responsible, how the clothes were collected or stored (in plastic or non plastic bags) was not reported. Whether the survivor took a bath before arrival was documented in only two cases.

Hospital records documented that $83 / 85$ of survivors had a genital examination. For half of the cases no physical injuries were documented, which is not uncommon in many rape cases. Some survivors had multiple injuries. 
Table 1: Types of injuries $(\mathrm{N}=83)$

\begin{tabular}{|l|l|l|}
\hline Types of injuries & Number & Percentage \\
\hline Normal / no visible injuries/intact & 43 & 52 \\
\hline Broken/bruised hymen & 19 & 23 \\
\hline Anal bruised/Penetration & 3 & 4 \\
\hline tears/bruises/injuries to genitalia & 19 & 23 \\
\hline FGM scar & 13 & 16 \\
\hline Genital discharge & 18 & 22 \\
\hline Hymen not intact & 14 & 17 \\
\hline Other & 8 & 10 \\
\hline
\end{tabular}

\section{Medical Management}

At the hospital, all survivors of rape are expected to receive antibiotics as a presumptive treatment of sexually transmitted diseases such as syphilis, gonorrhoea, and Chlamydia. All survivors are also expected to be provided with post exposure prophylaxis (PEP) for HIV, emergency contraception (EC) and tetanus and hepatitis B vaccines. However, that is not practice in Wajir as shown in the table below.

Table 2: Medical care provided to survivors

\begin{tabular}{|c|c|c|}
\hline \multicolumn{2}{|l|}{ Type of care provided } & $\mathrm{N}=87$ \\
\hline \multicolumn{2}{|l|}{ Antibiotics prescribed } & 21 \\
\hline \multicolumn{2}{|l|}{ Post exposure prophylaxis prescribed } & 12 \\
\hline \multicolumn{2}{|l|}{ Tetanus prescribed } & 9 \\
\hline \multicolumn{2}{|l|}{ Analgesics prescribed } & 23 \\
\hline \multicolumn{2}{|l|}{ Emergency contraception prescribed } & 10 \\
\hline Was there any reported injuries? & Yes & 11 \\
\hline If yes any stitching / surgery performed? & No & 4 \\
\hline
\end{tabular}

The following issues concerning medical management emerged during the validation workshop:

- Many staff do not know the required HIV PEP dosage; the majority thought that it is only administered once.

- Few survivors were tested for pregnancy, STI and HIV

- If a survivor tested HIV negative, some staff thought that they do not require PEP.

- PEP and EC are not readily available.

- Lack of a counselling facility at the hospital.

- None of the survivors who reported to hospital received the Hepatitis B vaccine.

Ideally, all survivors of sexual violence should be tested for HIV, pregnancy and sexually transmitted infections (STI). However, only 12 survivors were offered a test for HIV and only two of these actually had the test. Only eight survivors were tested for pregnancy (see table below). The need for capacity building of health workers in medical care and psycho-social support was stressed upon. 
Table 3: Medical care provided:

\begin{tabular}{|c|c|c|}
\hline \multicolumn{2}{|l|}{ Laboratory services offered } & $\mathrm{N}=87$ \\
\hline \multicolumn{2}{|l|}{ HIV test offered } & 12 \\
\hline \multicolumn{2}{|l|}{ STI tests offered } & 8 \\
\hline \multicolumn{2}{|l|}{ Survivors being tested for HIV } & 2 \\
\hline \multicolumn{2}{|l|}{ Anal swab done at Health Facility Lab } & 1 \\
\hline \multicolumn{2}{|l|}{ Skin swab done at Health Facility Lab } & 1 \\
\hline \multicolumn{2}{|c|}{ Blood sample collected at Health Facility Lab } & 2 \\
\hline \multirow[t]{2}{*}{ Pregnancy test } & Done at National Government Lab & 2 \\
\hline & Done at Health Facility Lab & 6 \\
\hline External vaginal swab for sperm & Done at Health Facility Lab & 1 \\
\hline \multirow[t]{2}{*}{ Internal (high) vaginal swab for sperm } & Done at National Government Lab & 3 \\
\hline & Done at Health Facility Lab & 8 \\
\hline
\end{tabular}

\section{Judiciary services}

According to the police and judiciary staff interviewed, all sexual offenses cases are heard privately, expeditiously and in reasonable time.

At the judiciary, only 50/57 cases were retrieved and went through the legal justice system. Out of these, there were 23 convictions and 15 acquittals. Eight and four cases were pending and withdrawn respectively at the time of the study. Two cases were referred to Mathare Mental Hospital for mental assessment. The duration between launching a case and its first hearing varied tremendously, from the same day to one year. Of the 50/57 cases filed at the judiciary, 35 (the majority) were heard within one month from the launch of the case at the judiciary. None of the survivors had their own legal representation and so were represented by the court prosecutor, who usually is a police officer.

\section{Verdict at the Wajir Magistrate court}

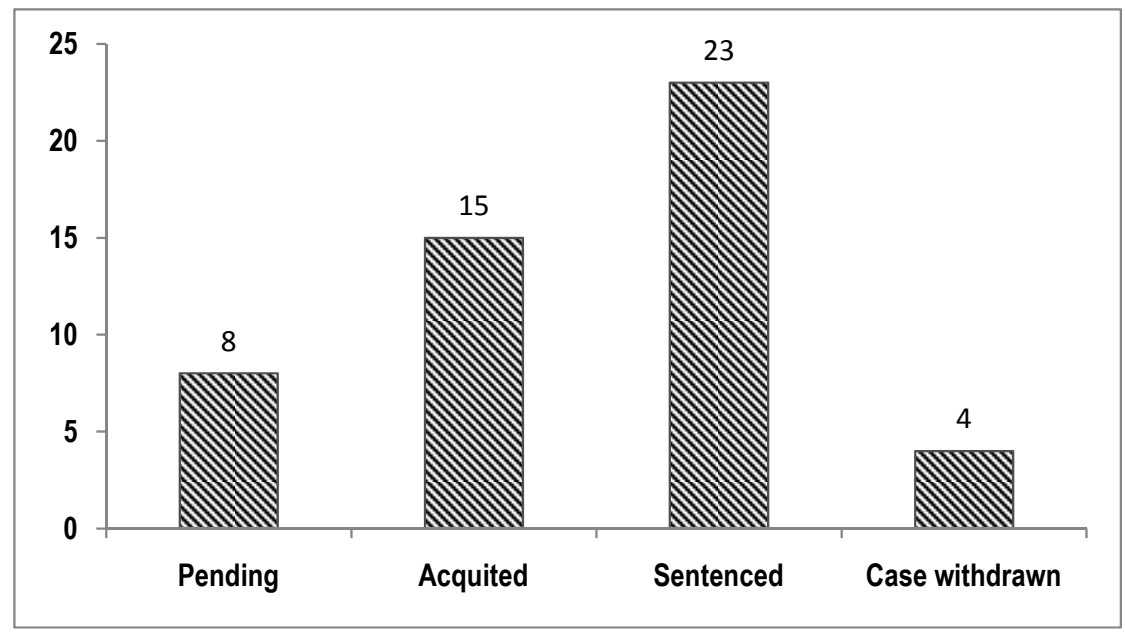

P3 forms were the main source of documented evidence used. Other types of physical evidence presented included knives, other weapons, and clothes. Most witnesses were police and medical officers. However, nurses and clinical officers indicated that they do not like to appear in court as witnesses, because it takes too much time. 
According to police records, punitive measures applied for the cases found guilty ranged from six months community service to 50 years imprisonment. In 16 cases there was insufficient and/or inadmissible evidence (as stipulated under sections 204 and 215 of the Criminal Penal Code Act respectively) and so the accused were acquitted. This act was previously applied to all sexual offenses before the sexual offenses Act (2006) were legislated. 'We don't have the full capacity to handle cases we lack forensic laboratories and equipment to test the evidence. Lack of technology forces us to parade 10 suspects in order for the victim to identify the assailant" (Police officers FGD).

Insensitive and unfriendly court procedures can deter women from seeking legal redress. According to one female member of a local NGO, "Most of them (survivors) do not go to court because of the nature of questions asked which are very difficult to answer e.g. How long the penis was. When the girl keeps quiet the court is adjourned. I am speaking of a case I witnessed "(FGD NGOs/CBOs).

\section{Kadhi courts}

Kadhi is an Arabic term that refers to a judge. In Kenya it specifically means a Muslim magistrate who has the power of adjudicating civil disputes according to Islamic law, otherwise referred to as Shariah law. The Kadhi Court has been in operation since before Kenya's independence, although with limited jurisdiction, and has been operating under Kenya's present constitution since 1963. The court's jurisdiction is limited to determination of questions of Muslim Law relating to personal status, marriage, divorce or inheritance in proceedings in which all parties are Muslims. There are about $17 \mathrm{Kadhi}$ courts nationwide.

In Wajir, the Kadhi court handles cases related to divorce, property inheritance, child maintenance and dowry $(\text { Mahar })^{2}$. Records indicate that divorce cases take up 42 percent of the 206 cases reviewed and according to the Kadhi, more women are now petitioning divorce.

Reasons attributed to rising divorce include negligence, intimate partner violence, marital rape and demands for anal sex by husbands.

\section{Nature of claims at the Kadhi court}

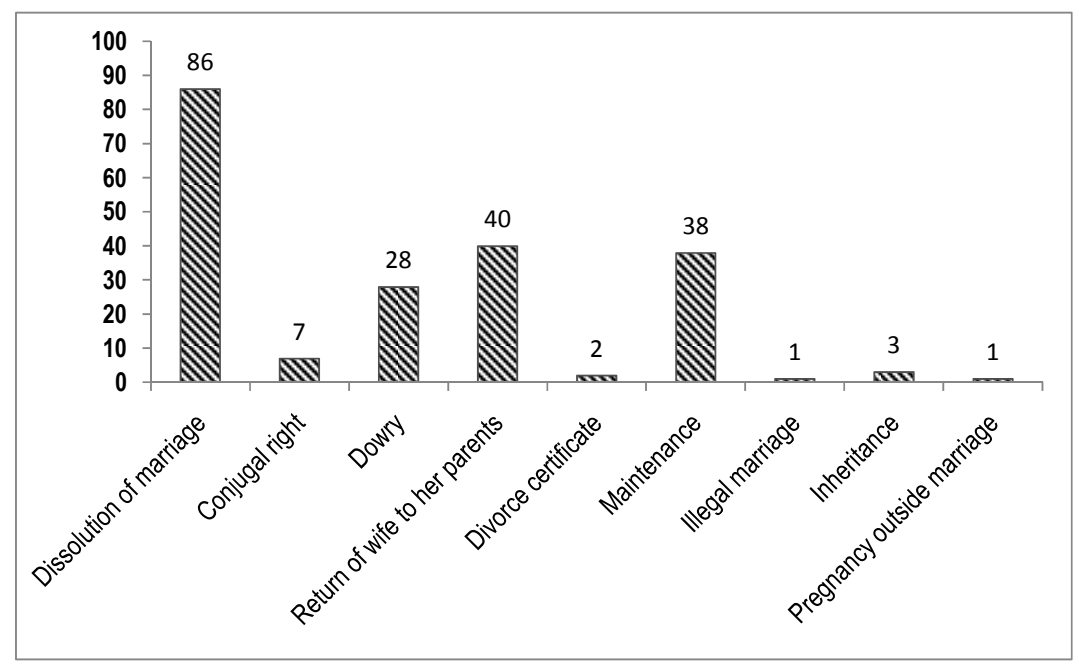

2 Dowry (Mahar) is a gift for the bride that is obligatory for the man and is a pre-condition for marriage. In the Somali community is paid after dissolution of marriage, unlike in other communities where it is used to solemnize and legitimize the marriage. 


\section{CURRENT AND PREFERRED SERVICES FOR SEXUAL VIOLENCE}

\section{Current model for responding to sexual violence}

It is evident that the current services model combines both traditional and formal responses to sexual and intimate partner violence. These two operate as parallel systems, with the perception that most of the cases are not reported to police but are resolved using the maslaha system. The study established that the maslaha system exists but operates on an ad hoc basis. Unlike other traditional structures, anyone can be a part of maslaha as long as they have attained middle age. It is constituted and dismantled as needed for dispute resolution as they arise. The system is also clan-based and even though it has no formal structure, it is powerful in its governance and dispute resolution affairs. Data were not collected on any SGBV cases handled by maslaha, but information was gathered about some punitive measures given to perpetrators of sexual violence (see section on dispute resolving mechanisms in the community). It is important to note that key informants interviewed from the Judiciary and police emphasised the need to better understand how the maslaha system operates to identify ways in which the formal and informal systems can complement each other.

The table below summarizes the key aspects of the current response model and highlights some of the key gaps or issues at each level.

Table 4: Current intervention model for sexual and intimate partner violence

\begin{tabular}{|c|c|c|}
\hline Response & Current intervention/ set up & Gaps identified \\
\hline 1.Community & $\begin{array}{l}\text { Survivor reports to parents, usually } \\
\text { the mother. } \\
\text { Most wash clothes and bathe, } \\
\text { destroying evidence } \\
\text { Reports to chief, maslaha or police. } \\
\text { Survivor or her clan compensated } \\
\text { with goats, money or new clothes. } \\
\text { Perpetrator's clan raise money or } \\
\text { cattle for compensation. } \\
\text { Wounds are treated with malmal } \\
\text { (Mixture of sticky traditional herbs } \\
\text { used to heal wounds) and hot water }\end{array}$ & $\begin{array}{l}\text { maslaha does not act as deterrent to sexual } \\
\text { violence; the perpetrator's clan contributes or pays } \\
\text { his fine. } \\
\text { Evidence is always lost at community level } \\
\text { Legal and medical services are sought way after } \\
\text { the } 72 \text { hour window period, increasing chances of } \\
\text { contracting HIV and other STIs. } \\
\text { Little awareness in community on what to do/ not } \\
\text { do and where to go after one has been raped. } \\
\text { Late reporting by survivors } \\
\text { Skewed justice favouring perpetrators } \\
\text { Discriminating young girl's limited access to school } \\
\text { make them vulnerable to rape and defilement. }\end{array}$ \\
\hline $\begin{array}{l}\text { 2. Police } \\
\text { services }\end{array}$ & $\begin{array}{l}\text { Record cases in occurrence book. } \\
\text { Open criminal case file and enter } \\
\text { case into criminal investigation } \\
\text { register. } \\
\text { Provides for P3 form at no charge } \\
\text { and accompanies survivors to } \\
\text { hospital. } \\
\text { Receives P3 form when duly filled } \\
\text { at hospital. }\end{array}$ & $\begin{array}{l}\text { Lack of computers to facilitate documentation. } \\
\text { Lacking record keeping facilities, impeding on } \\
\text { confidentiality. } \\
\text { Gender desk non functional } \\
\text { Need for Somali speaking }{ }^{3} \text { police to address } \\
\text { language and communication barrier. } \\
\text { maslaha obstructs collection of evidence. } \\
\text { Lack of storage facilities for evidence. } \\
\text { Long distance to travel to the government chemist }\end{array}$ \\
\hline
\end{tabular}

${ }^{3}$ Community shy away from reporting because most police at the station are not Somalis and therefore could not understand complains raised by survivors. 


\begin{tabular}{|c|c|c|}
\hline Response & Current intervention/ set up & Gaps identified \\
\hline & $\begin{array}{l}\text { Launches investigation. } \\
\text { Where applicable, apprehends } \\
\text { perpetrator. } \\
\text { Instigates legal proceedings at } \\
\text { Wajir courts. } \\
\text { Appears as witnesses/ court } \\
\text { prosecutor for survivor at the court. }\end{array}$ & $\begin{array}{l}\text { in Nairobi, making it difficult to travel, because of } \\
\text { resources needed (rape cases not prioritized). } \\
\text { Lacking capacity among police to handle cases. }\end{array}$ \\
\hline $\begin{array}{l}\text { 3. Medical } \\
\text { management }\end{array}$ & $\begin{array}{l}\text { Patient reports to OPD. } \\
\text { Is referred to police if s/he has not } \\
\text { been there. } \\
\text { Pays } 400 \text { Kshs for medical exam. } \\
\text { Medical exam performed and P3 } \\
\text { form filled. } \\
\text { Attended to by clinical officer in the } \\
\text { absence of the medical } \\
\text { superintendent. } \\
\text { Counselled and tested at VCT } \\
\text { (increasing stigma). } \\
\text { One dose of PEP is given } \\
\text { One dose of EC is provided. } \\
\text { Other treatment for STI. }\end{array}$ & $\begin{array}{l}\text { Guidelines for care and response not disseminated } \\
\text { to all hospital staff. } \\
\text { Service provided only during the day (no } 24 \text { hour } \\
\text { service). } \\
\text { Lack of rape register and proper documentation } \\
\text { Lack of adequate availability of PEP, EC and other } \\
\text { STI treatment and vaccines. } \\
\text { PRC forms unavailable } \\
\text { Lack of privacy in check up. } \\
\text { Lack of trained trauma counsellors to provide } \\
\text { psycho social care } \\
\text { Inadequate Staff capacities to respond. } \\
\text { No follow-up mechanism for treatment and } \\
\text { psycho-social support of survivors. }\end{array}$ \\
\hline 4. Judiciary & Presides over cases & $\begin{array}{l}\text { At times compromises are made. } \\
\text { Unfriendly intimidating procedures. } \\
\text { Lack of admissible evidence. } \\
\text { Ambiguity as to whether to apply the sexual } \\
\text { offenses act or the criminal procedure code. }\end{array}$ \\
\hline $\begin{array}{l}\text { 5. Kadhi } \\
\text { court }\end{array}$ & $\begin{array}{l}\text { Applies Shariah law on personal } \\
\text { matters }\end{array}$ & $\begin{array}{l}\text { Kadhi capacity to effectively deal with intimate } \\
\text { partner violence. }\end{array}$ \\
\hline
\end{tabular}

\section{Recommended model for responding to SGBV in Wajir District}

Participants in the study were invited to provide suggestions and recommendations for an improved response model that would better meet the particular needs of survivors in these communities. Many recommended that services for the medical management of sexual violence should be integrated into existing reproductive health or VCT services. Medical examinations could be done by trained nurses or medical officers, while VCT counsellors should be trained in trauma counselling relevant to rape. It was suggested that PEP for HIV needs to be made widely available.

Also noted was the need for stronger linkages between the police and district hospital, with trained and designated staff assigned to deal specifically with survivors at each institution. The need to build institutional and staff capacities at health, judiciary, Kadhi court and police to help them offer better services was identified, coupled with clear guidelines and protocols at all institutions.

Community members expressed the feeling that religious leaders have a key role to play in prevention of rape and defilement, through sensitization of communities on Islam's position on rights of girls and women and on sexual violence and IPV. Community members also suggested that the maslaha should desist from engaging in sexual violence or IPV cases. 
A draft framework for a more comprehensive and appropriate model of care, support and prevention of SGBV that emerged from discussions with community members, service providers and stakeholders is as follows:

1. Strengthened medical management at the $\mathrm{MCH}$ unit in Wajir district hospital with the following components:

- Counselling for and provision of pregnancy, STI and HIV testing.

- Work closely with the MOH/NACC to ensure provision of STI and HIV postexposure prophylaxis (PEP).

- Treating physical injuries.

- Provision of reproductive health information and emergency contraception.

- Lobby for waiver of $400 \mathrm{Kshs}$ charge for examination of survivors.

2. Introduce psychological counselling of rape survivors at $\mathrm{MCH}$ clinic, by $\mathrm{MCH}$ nurse counsellors trained in trauma counselling to reduce stigma.

3. Equip prosecutors with skills that will help them to use sensitive approaches for cross examining child survivors of defilement.

4. Train judicial and police staff in how to handle survivors, writing charge sheets and utilizing the sexual offences Act.

5. Train community paralegal officers affiliated with human rights organizations in Wajir, to give legal counselling to survivors.

6. Designate medical staff to be available to provide evidence in court.

7. Explore innovative ways to handle child and male survivors of sexual violence.

8. Institute forensic laboratories at the District Hospital.

9. Ensure that sexual violence cases are heard in private chambers at Wajir Magistrates court.

10. Establish strong links between police and hospital to enable incidents to be referred in either direction so that, if desired, a prosecution can be initiated.

11. Institute rape registers at hospitals and police and hospital and functional filing systems.

12. Sensitize communities that P3 and PRC 1 forms are issued free for sexual violence survivors.

13. Use mass media, including vernacular radio stations such as Star FM, to sensitize the public of which services are available and what or what not to do.

14. Develop new, or strengthen existing, community-based prevention activities, such as:

- Establish a network of NGOs and CBOs to sensitize the community on strategies that are relevant and appropriate and to act as referral mechanism to link survivors to existing services.

- Involve religious leaders in promoting rights of women and girls not to be violated.

- Advocate for universal enrolment of girls in primary and secondary schools.

15. Enhance religious scholar's capacities to ameliorate arbitration of sexual violence cases by maslaha.

16. Ensure that physical (and psychological/emotional) violence between domestic or intimate partners is addressed.

17. Building capacity of Kadhi to probe and address intimate partner violence. 


\section{REFERENCES}

African Regional Sexuality Resource Centre. 2006. Sexuality in the media, Emerging issues in Africa: Research on Africa's print media.

Baker, L. 2007. Gender-based Violence Case Definitions: Towards Clarity in Incident Classification. International Research Committee: circulated paper.

Betron, M. \& E. Doggett. 2006. Linking Gender-Based Violence Research to Practice in East, Central and Southern Africa: A Review of Risk Factors and Promising Interventions. USAID/POLICY Project, Washington, DC.

Bott, S., Morrison, A. and M. Ellsberg. 2005. Preventing and Responding to Gender-based Violence in Middle and Low-income Countries: A Global Review and Analysis. World Bank Working Paper Series 3618. Washington, DC: World Bank.

Campbell, R \& T. Self. 2004, "The Impact of Rape on Women's Sexual Health Risk Behaviours", Health Psychology, vol. 23, no. 1, pp. 67-74.

Global AIDS Alliance (GAA). 2006. Zero Tolerance: Stop the Violence Against Women and Children, Stop HIV/AIDS. Washington, DC: Global AIDS Alliance.

Guedes, A. et al. 2002. "Gender-based violence, Human Rights and the Health Sector: Lessons from Latin America", Health and Human Rights. Vol. 6 (1): 177-194.

IGWG of USAID. 2006. Addressing Gender-Based Violence through USAID's Health Programs: A Guide for Health Sector Program Officers. Washington, DC.

Kaiser Daily HIV/ AIDS report 1/7; 2008.

Keesbury, J., Skibiak, J. \& M. Zama. 2006. "Reducing unwanted pregnancy among victims of sexual assault: New windows of opportunity for Emergency Contraception”, Draft paper: Population Council: Lusaka, Zambia.

Kilonzo, N. 2003. Conceptualizing Vulnerability to Sexual Violence \& HIV : Implications for Practical Responses. LVCT \& CARE.

Kilonzo N et al. 2007. HIV PEP uptake among sexual assault survivors: results of an observational study. Fourth International AIDS Society Conference on HIV Treatment and Pathogenesis, Sydney, Australia, abstract MOPDC04.

Pelser, E. et al. 2005. Intimate Partner Violence: Results from a National Gender-Based Violence Study in Malawi. Crime \& Justice Statistical Division, National Statistical Office.

Sperry L. \& Carlson J. 1996. Psychopathology and Psychotherapy, Taylor and Francis Group.

UN-GASS, 2006. UN Secretary General. Report on Violence against Women. United Nations, New York.

World Health Organization. 2003. Protocols for the medical management of persons who experienced sexual violence. Geneva: WHO.

World Bank. 2006. Reducing Violence against Women: Justice Sector Perspectives. Sector Operational Guide for the World Bank Gender and Development Group. 
Gender Equity Support Project (GESP II)

Canadian Cooperation Office

$1^{\text {st }}$ Floor, Purshottam Place

Westlands Road

P.O. Box 1591 - 00606

Nairobi, Kenya
Population Council

$2^{\text {nd }}$ floor General Accident House

Ralph Bunche Rd

P.O. Box 17643 - 00500

Nairobi, Kenya 